\title{
EFFECTIVENESS OF EDUCATION USING HA-MAN MODULE ON SELF-EFFICACY OF ADULTS IN PREVENTING CORONARY HEART DISEASE
}

\section{EFEKTIVITAS EDUKASI MELALUI MODUL HA- MAN TERHADAP EFIKASI DIRI KELOMPOK USIA DEWASA DALAM MENCEGAH PENYAKIT JANTUNG KORONER}

\author{
Ni Kadek Ayu Suarningsih ${ }^{1}$, I Kadek Saputra ${ }^{2}$ \\ ${ }^{1,2}$ Program Studi Ilmu Keperawatan dan Profesi Ners, Fakultas Kedokteran, \\ Universitas Udayana, Indonesia
}

\begin{abstract}
ABSTRAK
Setiap tahun terjadi peningkatan signifikan kematian yang disebabkan oleh penyakit jantung koroner (PJK). Berbagai upaya telah dilakukan untuk menurunkan morbiditas dan mortalitas PJK. Deteksi dini dan pengendalian faktor-faktor risiko PJK merupakan sebuah tantangan dalam edukasi perubahan gaya hidup kelompok usia dewasa. Selain itu, telah diketahui bahwa efikasi diri adalah faktor vital dalam memulai dan mempertahankan perilaku kesehatan. Edukasi kesehatan diberikan sebagai upaya meningkatkan efikasi diri namun media edukasi yang inovatif pada promosi kesehatan PJK masih terbatas. Penelitian ini bertujuan untuk mengetahui perbedaan efikasi diri kelompok usia dewasa dalam mencegah penyakit jantung koroner sebelum dan setelah diberikan edukasi melalui modul HA-Man. Penelitian ini merupakan penelitian quasi-eksperimen dengan rancangan pretest-postest control group design. Sampel berjumlah 60 responden dengan masing-masing 30 responden pada kelompok intervensi dan kelompok kontrol yang diperoleh melalui purposive sampling. Intervensi edukasi HA-Man diberikan 3 kali selama satu minggu, sementara efikasi diri dievaluasi melalui wawancara dengan kuesioner terstruktur. Hasil penelitian ini menunjukan perbedaan bermakna self efficacy sebelum dan setelah intervensi pada kelompok intervensi $(\mathrm{p}<0,05)$. Penelitian ini diharapkan dapat memberikan informasi dalam pengembangan media edukasi untuk meningkatkan kesadaran dan efikasi diri masyarakat yang berisiko PJK.
\end{abstract}

Kata Kunci: Edukasi Kesehatan, efikasi diri, Heart Attack, Penyakit jantung Koroner

\footnotetext{
ABSTRACT

Every year, there is a significant increase in deaths caused by coronary heart disease (CHD). Many programs have been implemented to reduce the morbidity and mortality of CHD. Early detection and control of CHD risk factors is a challenge in educating adults about lifestyle changes. Also, it is recognized that self-efficacy is a vital factor in initiating and maintaining healthy behaviors. Health education is given as an effort to increase selfefficacy, but educational media that are innovative in promoting CHD health are limited. This study aimed to determine differences in the self-efficacy of adults in preventing
} 
coronary heart disease before and after given health education. This was a quasiexperimental study with a pretest-posttest control group design. The sample were 60 respondents which were grouped into 30 respondents in the intervention group and control group through purposive sampling. The HA-Man education intervention was given 3 times for a-week, self-efficacy was evaluated through a structured questionnaire interview. The results showed that there were differences in self-efficacy before and after intervention in the intervention group $(p<0.05)$. This research is expected to provide information in the development of educational media in increasing awareness and self-efficacy of people who are at risk of $C H D$.

Keywords: Health education, self-efficacy, Heart Attack, Coronary heart disease

\begin{tabular}{ll}
\hline Alamat Korespondensi & : STIKes Wira Medika Bali \\
Email & : ayusuarningsih@unud.ac.id
\end{tabular}

\section{PENDAHULUAN}

Penyakit kardiovaskular masih menduduki peringkat tertinggi penyebab kematian di seluruh dunia. Data Riset Kesehatan Dasar (Riskesdas) tahun 2018, menggambarkan prevalensi penyakit jantung dan pembuluh darah semakin meningkat setiap tahunnya. Penyakit Jantung Koroner (PJK) merupakan penyebab utama dan pertama dari seluruh kematian yang ada di Indonesia yaitu sebesar 26,4\%, dimana empat kali lebih besar dibandingkan angka kematian pada kanker (6\%) (Yahya, 2010). Dengan kata lain, kurang lebih satu diantara empat orang yang meninggal di Indonesia disebabkan oleh PJK. Banyak faktor yang berkaitan dengan tingginya insidensi PJK seperti hambatan untuk mengakses layanan kesehatan, sosial ekonomi, tingkat pendidikan, dan kesadaran akan kesehatan serta pola hidup yang tidak sehat.

PJK terjadi apabila suplai darah ke otot jantung terganggu (WHO, 2014) Penelitian menyebutkan PJK dapat dicegah hingga sekitar 80\% (TabatabaeiMalazy et al., 2014). Pencegahan PJK baik primer maupun sekunder berhubungan erat dengan pengendalian faktor risiko antara lain hipertensi, dislipidemia, dan diabetes mellitus (Rezazadeh et al., 2010), perubahan gaya hidup seperti berhenti merokok, diet yang tepat, penurunan berat badan, tekanan darah rendah, aktivitas fisik, dan pengurangan stres adalah strategi yang paling efektif untuk mencegah atau menunda berkembangnya PJK. Selain itu, pengendalian gaya hidup memiliki peranan lebih penting daripada mengontrol faktor genetic (Alwaili et al., 2009).

Pengetahuan penyakit memberikan kontribusi terhadap pemahaman akurat tentang penyakit dan meningkatkan kepatuhan terhadap gaya hidup sehat guna mencegah PJK (Mosca et al., 2006). Pengalaman memperoleh edukasi kesehatan dan kesadaran akan faktor-faktor risiko PJK secara statistik berpengaruh signifikan terhadap self-efficacy (efikasi diri). Semakin tinggi pengetahuan akan semakin meningkatkan efikasi diri pasien PJK (Wantiyah, 2010). Efikasi dari adalah faktor vital dalam memulai dan mempertahankan perilaku kesehatan yang mengacu pada keyakinan seseorang dalam kapasitasnya untuk melakukan perilaku yang diperlukan sehingga menghasilkan pencapaian kinerja tertentu (Bandura, 1997). 
Beberapa penelitian menunjukan edukasi melalui booklet, leaflet, dan video efektif dalam peningkatkan pengetahuan. Selain itu, pemilihan media edukasi yang tepat dapat mengubah perilaku seseorang. Sedangkan paparan edukasi yang efektif memiliki kaitan dengan peningkatan pengetahuan, perubahan sikap, dan efikasi diri (Witte, Jarato, \& Menard, 2005). Penelitian ini bertujuan untuk mengetahui efektivitas pemberian edukasi melalui Modul Heart Attact Manual (HA-Man) terhadap efikasi diri kelompok usia dewasa dalam mencegah PJK.

\section{METODE PENELITIAN}

Penelitian ini merupakan penelitian Quasi Experiment dengan rancangan pretest-postest control group design. Penelitian dilakukan pada dua kelompok yaitu masing-masing 30 responden pada kelompok intervensi dan kelompok kontrol. Dengan kriteria inklusi a) berusia 26-45 tahun, b) Memiliki faktor risiko PJK seperti: Diabetes, Hipertensi, dan Dislipidemia, c) Belum pernah terdiagnosis PJK. Individu yang tidak bisa membaca dan menulis serta memiliki gangguan pendengaran tidak dikutsertakan dalam penelitian. Penelitian dilaksanakan pada bulan Agustus-Oktober 2019 di wilayah kerja Puskesmas III Denpasar Utara. Efikasi diri diukur sebelum intervensi menggunakan 3 kuesioner terstruktur yaitu General self-efficacy/GSE (Born, Schwarzer, \& Jerusaem, 1995), Cardiac SelfEfficacy/CSE (Sullivan et al, 1998) dan Cardiac Diet Self-Efficacy/CDSE (Hickey, Owen, \& Froman, 1992) dengan nilai validitas dan reliabibilitas baik (Wantiyah, 2010). Gabungan kuesioner ini terdiri atas 45 item pertanyaan dengan 4 poin skala linkert.

Kelompok intervensi diberikan edukasi berupa modul HA-Man dalam tiga sesi selama satu minggu sementara kelompok kontrol hanya diberikan informasi ketika pertama kali kunjungan. Efikasi diri diukur kembali setelah responden menyelesaikan intervensi. Analisis data menggunakan uji t untuk mengetahui pengaruh intervensi terhadap efikasi diri pada kelompok kontrol dan perlakuan dengan tingkat kepercayaan 95\%.

\section{HASIL DAN DISKUSI}

\section{HASIL}

Pada penelitian ini usia rata-rata responden kelompok usia dewasa pada kelompok kontrol 37,04 tahun dan usia rata-rata pada kelompok intervensi adalah 39,47 tahun. Mayoritas jenis kelamin pada kedua kelompok kontrol $(43,3 \%)$ dan kelompok intervensi $(56,7 \%)$ adalah laki-laki. Lebih dari setengah tingkat pendidikan responden pada kelompok kontrol dan intervensi yaitu SMA dan perguruan tinggi/akademik. Responden dikedua kelompok sebagian besar sudah menikah, sementara hanya sebagian kecil dari masing-masing kelompok Kontrol $(16,7 \%)$ dan kelompok intervensi $(2,3 \%)$ yang tidak bekerja. Sebagian besar reponden di kedua kelompok memiliki penyakit risiko PJK seperti Hipertensi. Hasil statistik lebih lanjut menyimpulkan tidak ada perbedaan yang signifikan menurut karakteristik responden antara kelompok kontrol dan kelompok intervensi. 
Tabel 1. Efikasi diri Sebelum dan Setelah Intervensi Modul Ha-Man pada Kelompok Intervensi

\begin{tabular}{lcccccc}
\hline \multirow{2}{*}{ Variabel } & \multicolumn{2}{c}{$\begin{array}{c}\text { sebelum Intervensi } \\
(\mathrm{n}=30)\end{array}$} & \multicolumn{2}{c}{$\begin{array}{c}\text { Setelah Intervensi } \\
(\mathrm{n}=30)\end{array}$} & $t$ & $p$ \\
& $\mathrm{M}$ & $\mathrm{SD}$ & $\mathrm{M}$ & $\mathrm{SD}$ & & \\
\cline { 2 - 6 } & 131.13 & 13.87 & 148.53 & 12.55 & 9.07 & .000 \\
$\begin{array}{l}\text { Total Efikasi } \\
\text { Diri }\end{array}$ & & & & & & \\
\hline GSE & 28.67 & 4.74 & 31.60 & 4.09 & 3.81 & .001 \\
\hline CSE & 59.87 & 11.19 & 67.00 & 8.80 & 5.82 & .000 \\
\hline CDSE & 42.60 & 5.71 & 49.93 & 6.39 & 4.90 & .000 \\
\hline
\end{tabular}

Tabel 1 menunjukkan efikasi diri sebelum dan setelah pemberian edukasi melalui Modul HA-Man pada kelompok intervensi. Terdapat perbedaan signifikan secara statistik efikasi diri sebelum dan setelah edukasi pada kelompok intervensi $(t=9,07 ; p<0,05)$, perbedaan efikasi diri juga meliputi masing-masing komponen GSR, CSE, dan CDSE $(p<0,05)$.

Hasil analisis uji independen $t$ test menunjukan terdapat perbedaan bermakna rata-rata efikasi diri total kelompok usia dewasa pada kelompok kontrol dan kelompok intervensi $(t=4,62 ; p<0,05)$, meskipun demikian nilai rata-rata GSE tidak berbeda secara signifikan $(t=0,389 ; p>0,05)$.

Tabel 2. Efikasi diri Setelah Intervensi Modul HA-Man pada Kelompok Kontrol dan Kelompok Intervensi

\begin{tabular}{lcccccc}
\hline \multicolumn{1}{c}{ Variabel } & \multicolumn{2}{c}{$\begin{array}{c}\text { Kelompok Intervensi } \\
(\mathrm{n}=30)\end{array}$} & $\begin{array}{c}\text { Kelompok Kontrol } \\
(\mathrm{n}=30)\end{array}$ & $t$ & $p$ \\
\cline { 2 - 5 } & $M$ & $S D$ & $M$ & $S D$ & & \\
\hline $\begin{array}{l}\text { Total Efikasi } \\
\text { diri }\end{array}$ & 148.53 & 12.55 & 134.33 & 11.21 & 4.62 & .000 \\
\hline GSE & 31.60 & 4.09 & 30.77 & 3.31 & .87 & .389 \\
\hline CSE & 67.00 & 8.80 & 61.33 & 8.06 & 2.60 & .012 \\
\hline CDSE & 49.93 & 6.39 & 42.23 & 6.80 & 4.51 & .000 \\
\hline
\end{tabular}

\section{PEMBAHASAN}

Peningkatan usia pada seseorang termasuk salah satu faktor resiko terjadinya PJK. Pada penelitian ini rata-rata kelompok usia dewasa pada kedua kelompok berusia diatas 37 tahun. Tanda dan gejala PJK terjadi umumnya pada orang yang umurnya diatas 40 tahun (Black \& Hawks, 2009). Penelitian Steigelman et al (2006) menyebutkan bahwa usia 30 - 60 tahun merupakan usia yang rentan untuk terserang PJK.

Salah satu faktor yang dapat mempengaruhi efikasi diri dalam melakukan pencegahan terhapat PJK adalah tingkat pengetahuan. Apabila seseorang memiliki pengetahuan yang baik mengenai PJK maka efikasi diri dalam pencegahan PJK akan semakin baik (Wantiyah, 2010). Penelitian ini menunjukan terdapat perbedaan bermakna efikasi diri sebelum dan setelah intervensi pada kelompok intervensi $(p<0,05)$. Penelitian sebelumnya menyebutkan pada pasien PJK, efikasi diri dikaitkan dengan kemampuan individu melalui keyakinan diri untuk melakukan 
perilaku yang dapat membantu pengelolaan faktor resiko dan pemeliharan fungsi kesehatannya (Wahyuni \& Rezkiki, 2015; Wantiyah, 2010).. Pengelolaan faktor resiko dan pemulihan kesehatan penting difokuskan pada individu dalam melakukan pencegahan PJK. Pemberian Edukasi dengan HA-Man yang merupakan edukasi terstruktur mengenai PJK mampu membuktikan adanya peningkatan keyakinan diri dalam melakukan perubahan perilaku terhadap faktor-faktor risiko PJK.

HA-Man merupakan sebuah booklet yang disusun untuk memudahkan pasien memahami faktor risiko PJK sehingga mampu melakukan pencegahan secara dini. Hasil penelitian ini sejalan dengan penelitian sebelumnya yang dilakukan oleh Unsual dan Kasicki (2010) pada populasi yang berbeda, penelitian tersebut menyebutkan edukasi terstruktur dengan booklet secara signifikan meningkatkan efikasi diri individu dengan baik. Efikasi diri tidak terlepas dengan tingkat pengetahuan, pada penelitian ini sebagian besar responden memiliki tingkat pendidikan yang memadai untuk memahami edukasi yang diberikan sehingga efikasi diri dapat lebih mudah dicapai. Namun, jumlah sampel yang masih minimal dalam penelitian ini mungkin memberikan dampak terhadap hasil penelitian, penelitian dengan jumlah sampel lebih besar dapat dilakukan untuk mengetahui kefektifan media edukasi khususnya pada populasi PJK diberbagai setting pelayanan kesehatan.

\section{SIMPULAN DAN SARAN}

Penelitian ini berkontribusi dalam meningkatkan self-efficacy penduduk usia dewasa dalam mencegah PJK. Penelitian ini menemukan bahwa self-efficacy memiliki hubungan yang signifikan dengan perubahan perilaku. Intervensi edukasi melalui HA-Man positif mempengaruhi self-efficacy dimana konten dari materi HA-Man mampu secara persuasif meningkatkan pengetahuan mengenai PJK dengan aktivitas aktual dalam mengontrol faktor risiko PJK. Perawat diharapkan dapat memanfaatkan media edukasi yang informatif dalam pencegahan dini PJK.

\section{UCAPAN TERIMA KASIH}

Peneliti mengucapkan terimakasih kepada Universitas Udayana dalam memberikan bantuan dana berupa Hibah penelitian PNBP sehingga penelitian ini dapat berjalan sesuai rencana. Ucapan terima kasih juga peneliti sampaikan kepada para responden, asisten peneliti dan rekan sejawat di Program Studi Sarjana Keperawatan dan Profesi Ners, FK UNUD yang telah mendukung selama penelitian ini berlangsung.

\section{DAFTAR PUSTAKA}

Alwaili, K., Alrasadi, K., Awan, Z. \& Genest, J. (2009). Approach to the diagnosis and management of lipoprotein disorders. Current opinion in endocrinology, diabetes and obesity. 16(2): 132-140.

Bandura, A. (1997). Self-Efficacy: The exercise of control. W. H. Freeman, New York, USA. 
Born, Schwarzer, \& Jerusalem. (1995). Indonesia Adaptation of the General SelfEfficacy Scale. Diakses 26 Februari 2019 http://userpage.fuberlin.de/ health/indonese.htm

Hickey, M. L., Owen, S. V., \& Froman, R. D. (1992). Instrument development: cardiac diet and exercise self-efficacy. Nursing research, 41(6), 347-351.

Mosca, L., Greenberger, H. M., Dolor, R. J., Newby, K., \& Robb, K. J. (2006). National study of women's awareness, preventive action, and barriers to cardiovascular health. Circulation, 113, 525-534

Rezazadeh, A., Rashidkhani, B., \& Omidvar, N. (2010). Association of major dietary patterns with socioeconomic and lifestyle factors of adult women living in Tehran, Iran. Nutrition (Burbank, Los Angeles County, Calif.), 26(3), 337-341. https://doi.org/10.1016/j.nut.2009.06.019

Riset Kesehatan Dasar (Riskesdas) (2018). Badan Penelitian dan Pengembangan Kesehatan Kementerian RI tahun 2018. http://www.depkes.go.id/resources/download/infoterkini/materi_rakorpop 2018/Hasil\%20Riskesdas\%202018.pdf

Steigelman, K.L., Kimble, P. L., Dunbar, S., Sowell, L.R., \& Bairan, A. 2006. Religion, relationship, and mental health in mild life women following acute myocaldial infraction. Issues in mental Health Nursing, $27: 141$-159.

Sullivan, M.D., LaCroix, A.Z., Russo, J., \& Katon, W.J. (1988). Self-efficacy and self-reported functional status in coronary heart disease: A six-month prospective study. Psychosom Med, 60(4):473-8. https://doi.org/10.1097/00006842-199807000-00014.

Tabatabaei-Malazy O, et al. (2014). Prevalence of dyslipidemia in Iran: A systematic review and meta-analysis study. International journal of preventive medicine. 5 (4): 373.

Unsal, A., \& Kasikci, M. A,. (2010). Effect of education on perceived self efficacy for individuals with arthritis. International Journal of Caring Science. 3(1): $3-12$.

Wahyuni, Aria \& Rezkiki, Fitrianola. (2015). Pemberdayaan dan Efikasi Diri Pasien Penyakit Jantung Koroner melalui Edukasi Kesehatan Terstruktur. Jurnal Ipteks Terapan. 9. https://doi.org/10.22216/jit.2015.v9i1.26.

Wantiyah, Sitorus, R., \& Gayatri, D. (2010). Analisis Faktor-Faktor Yang Mempengaruhi Efikasi Diri Pasien Penyakit Jantung Koroner Dalam Konteks Asuhan Keperawatan Di RSUD Dr. Soebandi Jember. Tesis. FIKUI.

World Health Organization. (2020). Cardiovascular diseases. https://www.who.int/cardiovascular diseases/resources/atlas/en/

Witte, K., Jarato, K., \& Menard, T. (2005). The Effectiveness of Media Use in Health Education: Evaluation of an HIV/AIDS Radio Campaign in Ethiopia AU - Farr, A. Celeste. Journal of Health Communication, 10(3), 225-235. https://doi.org/10.1080/10810730590934244

Yahya, A.F.(2010). Menaklukkan Pembunuh no.1 : Mencegah dan Mengatasi Penyakit Jantung Koroner Secara Tepat.Bandung: PT Mizan Pustaka. 